\title{
Interferência de uma Comunidade de Plantas Daninhas com PredominânCIA de Ipomoea hederifolia NA CANA-SoCA ${ }^{1}$
}

\author{
Interference of a Weed Community with Predominance of Ipomoea hederifolia on Sugar Cane \\ Ratton
}

\begin{abstract}
SILVA, I.A.B. ${ }^{2}$, KUVA, M.A. ${ }^{3}$, ALVES, P.L.C.A. ${ }^{4}$ e SALGADO, T.P. ${ }^{5}$
RESUMO - Levantamentos recentes da flora de plantas daninhas associada à cultura da cana-de-açúcar apontaram Ipomoea hederifolia como uma das espécies mais importantes. Em virtude disso, objetivou-se determinar o potencial de redução da produtividade da canade-açúcar e da qualidade do caldo em resposta à interferência de uma comunidade de plantas daninhas com predomínio de I. hederifolia, bem como o periodo anterior à interferência (PAI). Foi instalado um experimento em Pitangueiras, SP, em que constituiram tratamentos nove periodos crescentes de convivência das plantas daninhas com a cultura $(0,16,30,44$, 69, 97, 135, 160, 188 e 229 dias após o cultivo e adubação e início da brotação - DAB). O delineamento experimental foi em blocos casualizados, com cada tratamento em quatro repetições. Concluiu-se que o potencial de redução do número final de colmos e de produtividade foi de $34 \%$ e $46 \%$, respectivamente. O PAI foi do início da brotação e se estendeu por 33 dias. Com o aumento do periodo de convivência com a comunidade infestante, houve antecipação do processo de maturação dos colmos, cujo caldo tendeu a apresentar maior valor de açúcar total recuperável (ATR). Com a redução de produtividade devido à interferência, o valor de ATR ha-1 tendeu a ser negativamente afetado.
\end{abstract}

Palavras-chave: competição, períodos de interferência, corda-de-viola, Sacharum sp.

ABSTRACT - Recent surveys on weed community associated with sugar cane have pointed Ipomoea hederifolia as one of the most important species. Thus, this work aimed to determine the potential for reducing the productivity and quality of sugar cane in response to weed community interference with a predominance of I. hederifolia, and the period prior to interference (PPI). An assay was installed in Pitangueiras, Brazil, with the treatments consisting of nine periods of coexistence of the weeds with the culture $(0,16,30,44,69,97,135,160,188$ and 229 days after cultivation and fertilization and days after sprouting). The experiments were arranged in a randomized block design, with each treatment in four repetitions. The potential to reduce the number of stems and productivity was found to be $34 \%$ and $46 \%$, respectively. The PPI lasted from sprouting up to 33 days. Increased coexistence period with the weed community led to anticipation of the process of maturation of the stems, whose broth tended to show higher total recoverable sugar (TRS) value. With productivity reduction due to interference, the TRS value ha-1 tended to be negatively affected.

Keywords: competition, interference periods, Ipomoea hederifolia, Sacharum $\mathrm{sp}$.

1 Recebido para publicação em 29.3.2008 e na forma revisada em 5.5.2009.

2 Engo-Agró-, Coordenador de tratos culturais, Grupo Virgolino de Oliveira S.A. Açúcar e Álcool. Av. Comendador Virgolino de Oliveira, s/n, Caixa Postal 58, 13972-170 Itapira-SP, <ivan.a.b.@terra.com.br>; ${ }^{3}$ Eng ${ }^{\circ}$-Agr ${ }^{\circ}$, Herbae Consultoria e Projetos Agrícolas Ltda., <mkuva@herbae.com.br>; ${ }^{4}$ Professor Assistente, Dr., do Dep. de Biologia Aplicada à Agropecuária, Universidade Estadual Paulista - UNESP, <plalves@fcav.unesp.br>; ${ }^{5}$ Eng ${ }^{0}-A g r o$, Herbae Consultoria e Projetos Agrícolas Ltda., <tpsalgado@herbae.com.br>. 


\section{INTRODUÇÃO}

Um conjunto de espécies de plantas daninhas conhecidas popularmente como cordasde-viola tem se destacado nas comunidades infestantes da cultura da cana-de-açúcar, particularmente em áreas de colheita de canacrua. Essas espécies pertencem aos gêneros Ipomoea e Merremia, da familia Convolvulaceae. Dentro do gênero Ipomoea destacam-se: I. hederifolia, I. quamoclit, I. nil, I. grandifolia e I. purpurea, enquanto no gênero Merremia destacam-se $M$. cissoides e $M$. aegyptia.

Estudos fitossociológicos realizados por Kuva (2007) em áreas de colheita mecanizada na região de Ribeirão Preto-SP indicaram a presença de quatro espécies de corda-de-viola entre as 15 principais plantas daninhas quanto à importância relativa, com destaque para Ipomoea hederifolia, que ocupou o segundo lugar nessa lista, sendo superada somente por Cyperus rotundus.

As sementes das cordas-de-viola apresentam grande quantidade de reserva e, ao germinarem, suas plântulas emergem sob camadas com quantidades variáveis de palha (Martins et al., 1999; Azania et al., 2002; Gravena et al., 2004). O desenvolvimento das plantas ocorre mesmo na fase de maior crescimento dos canaviais, e as plantas adultas se entrelaçam aos colmos e folhas, interferindo negativamente no desenvolvimento da planta, nas práticas culturais e na colheita (Azania et al., 2002). Por ocasião da colheita, seus frutos e suas sementes podem-se encontrar ainda ligados à planta-mãe, favorecendo a disseminação pela colhedora para médias e longas distâncias.

Apesar da importância das cordas-de-viola na cultura da cana-de-açúcar, resultados de pesquisa sobre o potencial de redução de produtividade de cana-de-açúcar e de períodos críticos de interferência, especificamente para comunidades predominantemente compostas por cordas-de-viola, são ainda limitados.

A interferência depende de diversos fatores. Alguns são relacionados à comunidade infestante, outros à cultura e outros às condições específicas em que ocorre a convivência entre a cultura e a comunidade infestante, principalmente às condições edafoclimáticas, que por sua vez podem ser modificados pelos sistemas de produção. Além disso, depende também da época e da extensão do período em que ocorre a convivência entre as plantas daninhas e a cultura (Pitelli, 1985).

Devido à grande importância que as cordas-de-viola têm alcançado na cultura da cana-de-açúcar, objetivou-se avaliar o desenvolvimento de $I$. hederifolia nessa cultura e o potencial de redução da produtividade do canavial por uma comunidade infestante formada predominantemente por essa espécie, para estimar o período anterior à interferência.

\section{MATERIAL E MÉTODOS}

O experimento foi realizado na Fazenda Floresta, da Usina Andrade, situada no município de Terra Roxa - SP. A variedade de cana cultivada no talhão foi a RB855536 e estava em seu quinto ciclo produtivo. Após a quarta colheita, realizada no dia 15 de outubro de 2005, quando o canavial estava iniciando a brotação, a área foi cultivada mecanicamente e realizou-se adubação com $300 \mathrm{~kg} \mathrm{ha}^{-1}$ de NPK (18-0,5-24).

Para garantir o estabelecimento de uma comunidade de plantas daninhas com predominância de I. hederifolia, foi aplicado o herbicida trifluralina em área total logo após o cultivo e adubação. Além disso, espécies diferentes de I. hederifolia que emergiram foram eliminadas nas primeiras semanas do experimento, por meio de monda seletiva.

Os tratamentos constituíram de nove períodos crescentes de convivência entre a cana-de-açúcar e a comunidade infestante, com predominio de $I$. hederifolia, além de um tratamento mantendo a cultura livre das plantas daninhas durante todo o ciclo. Esses nove períodos tiveram como limite inferior a data do cultivo e adubação e início da brotação (DAB), estendendo-se até 16, 30, 44, 69, 97, $135,160,188$ ou 229 DAB. Ao término de cada período de convivência concedido, foi realizado o controle das plantas daninhas nas parcelas correspondentes, mantendo-as livre da presença destas até a colheita. A eliminação da comunidade infestante e a manutenção das parcelas limpas, quando requeridas pelos tratamentos, foram realizadas por meio de capina manual com enxada. 
As parcelas consistiram de cinco linhas de cana-de-açúcar espaçadas de $1,5 \mathrm{~m}$, com $10 \mathrm{~m}$ de comprimento, totalizando $75 \mathrm{~m}^{2}$. Como área útil de amostragem, consideraramse $36 \mathrm{~m}^{2}$ centrais, deixando-se como bordadura 1,5 m de cada lado da parcela e $1 \mathrm{~m}$ nas duas extremidades.

No final de cada período de convivência foi realizada a caracterização da comunidade infestante, por meio de amostragem com quadrados vazados com $0,5 \mathrm{~m}$ de lado e área interna de $0,25 \mathrm{~m}^{2}$. Os quadrados foram lançados ao acaso por quatro vezes na área útil das parcelas, e as plantas contidas dentro dos limites do quadrado de amostragem foram coletadas de forma a se obter a densidade e a massa de matéria seca específica. A massa seca da parte aérea das plantas daninhas foi obtida secando-as em estufa com circulação forçada de ar a $70{ }^{\circ} \mathrm{C}$. Os dados de densidade e massa seca das plantas daninhas foram extrapolados para número de plantas e gramas de matéria seca por metro quadrado, respectivamente.

A estimativa da produção de cana-deaçúcar nas parcelas foi realizada por biometria, aos sete meses após a colheita anterior. A biometria foi realizada sem queima prévia da palha, contando-se o número total de colmos industrializáveis e o peso médio de dez colmos de cada uma das três linhas centrais das parcelas, evitando-se as bordaduras. Os dados obtidos foram extrapolados para toneladas de cana por hectare e, posteriormente, para porcentagem, estipulando como máxima a produção obtida no tratamento em que as plantas daninhas foram controladas durante todo o período. Por ocasião da colheita também foi retirada uma amostra composta de dez colmos de cada tratamento, para avaliação de características qualitativas do caldo. Essas análises foram realizadas pelo laboratório de análises tecnológicas de cana-de-açúcar da Usina Andrade, determinando-se os teores de fibra, brix, pureza do caldo e açúcar total recuperável (ATR).

Com os dados coletados referentes à comunidade infestante e à cultura da canade-açúcar, foram efetuadas análises de regressão. Na escolha das equações de regressão foram considerados a lógica do fenômeno biológico e o valor do coeficiente de determinação. Com base na equação de regressão da produção de cana, foi determinado o período anterior à interferência para o nivel arbitrário de tolerância de $5 \%$ de redução na produtividade da cana-de-açúcar, em relação ao tratamento mantido na ausência da planta daninha durante todo o ciclo.

\section{RESULTADOS E DISCUSSÃO}

A maior densidade total da comunidade infestante presente na área ocorreu na fase inicial do experimento (Figura 1), até cerca de 30 dias após o cultivo e adubação e início da brotação da cana (DAB). Em seguida, houve declínio gradativo na densidade de plantas até 229 DAB. Essa redução deveu-se à competição entre os indivíduos da comunidade infestante e destes com a cana-de-açúcar, assim como à eliminação seletiva das espécies diferentes de Ipomoea hederifolia, antes que acumulassem grande quantidade de matéria seca.

Analisando as densidades para as principais espécies, verificou-se que até $44 \mathrm{DAB}$ a comunidade de plantas daninhas foi composta por Brachiaria plantaginea e I. hederifolia (Figura 2). Entre 30 e 44 DAB, a densidade de $B$. plantaginea reduziu drasticamente; a partir de $69 \mathrm{DAB}$, a comunidade de plantas daninhas passou a ser monoespecífica, de $I$. hederifolia. A redução populacional de $B$. plantaginea ocorreu devido à eliminação manual seletiva (monda), conforme mencionado anteriormente.

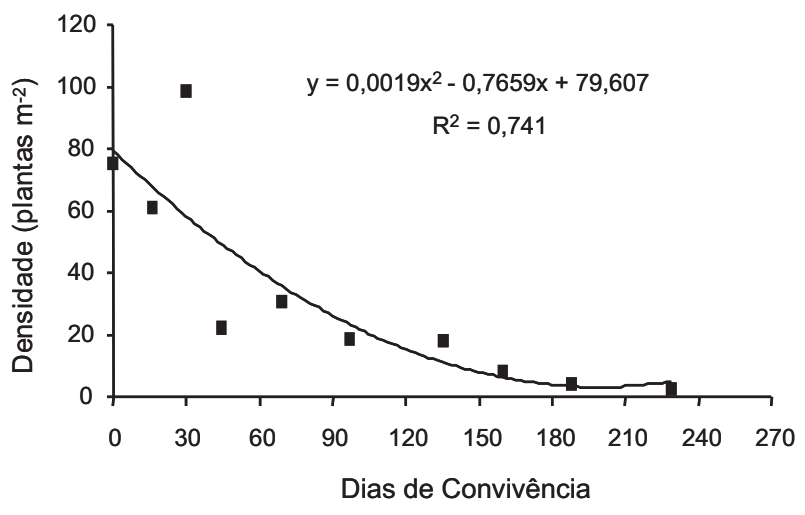

Figura 1 - Densidade total das plantas daninhas que compuseram a comunidade infestante ao final de cada período de convivência. 


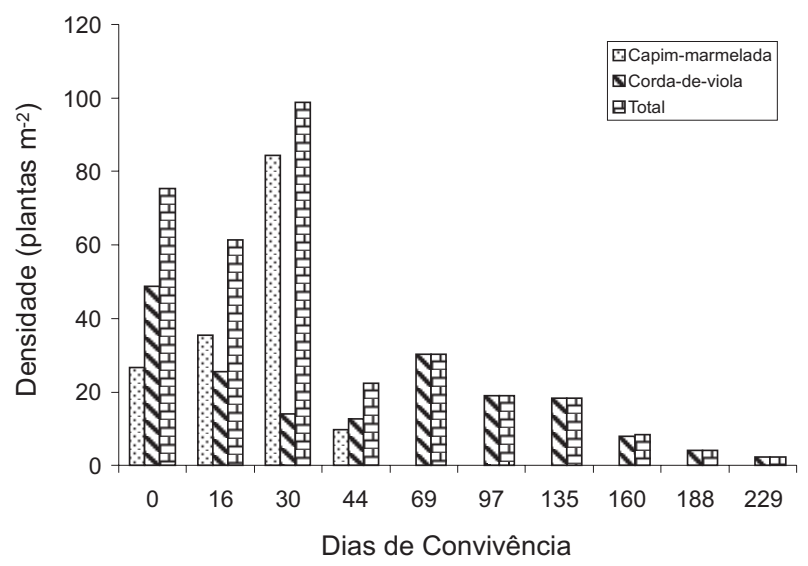

Figura 2 - Densidade das principais plantas daninhas que compuseram a comunidade infestante ao final de cada período de convivência.

Observou-se que $I$. hederifolia apresentou alta densidade inicial, seguida de decréscimo até $44 \mathrm{DAB}$ (Figura 2). Esse período correspondeu ao mês de novembro de 2005, quando a precipitação pluvial total foi pouco superior a $100 \mathrm{~mm}$, mas com distribuição ainda irregular. Nessas condições, as plântulas de I. hederifolia, que se mostraram altamente sensiveis e vulneráveis ao estresse hídrico, acabaram morrendo. Com o retorno à regularidade das precipitações pluviais - $140 \mathrm{~mm}$ em dezembro de 2005 e mais de $250 \mathrm{~mm}$ mensais em janeiro e fevereiro de 2006 - houve novo fluxo de emergência de I. hederifolia, e sua população atingiu cerca de 30 plantas $\mathrm{m}^{-2}$ aos 69 DAB. Posteriormente, com a ocorrência de competição intra e interespecífica, a densidade populacional voltou a reduzir gradativamente, até atingir o valor estimado de 2,33 plantas $\mathrm{m}^{-2}$ aos 229 DAB.

Segundo Kuva (2006), em áreas de colheita mecanizada sem queima prévia da palha, nas áreas colhidas na época mais úmida da safra na região de Ribeirão Preto-SP, a partir de meados de outubro, ocorreu grande aumento populacional de corda-de-viola imediatamente após o corte da cana. Em canaviais colhidos na época seca, meados de junho a final de agosto, houve um período de espera para o início da germinação, e numa época intermediária, entre meados de setembro e meados de outubro, os aumentos populacionais ocorreram em resposta à incidência de precipitações pluviais. Independentemente da época de corte, a maior população de corda-de-viola ocorreu ao redor de 120 dias após o corte.

A massa seca da comunidade infestante foi crescente à medida que os períodos iniciais de convivência aumentaram, atingindo, em média, mais de $400 \mathrm{~g} \mathrm{~m}^{-2}$ nas parcelas mantidas sem controle até a colheita (Figura 3). Verificou-se que a maior aceleração no aumento da massa seca ocorreu entre 44 e 135 DAB, estabilizando-se próximo a $440 \mathrm{~g} \mathrm{~m}^{-2}$; nesse período, a taxa de acúmulo de massa seca foi de $12 \mathrm{~g}$ por dia.

Considerando-se a massa seca de I. hederifolia (Figura 4), comportamento semelhante foi observado quando comparado à curva obtida para a comunidade infestante, ou seja, houve aumento em função dos períodos iniciais de convivência. Comparando as curvas das Figuras 3 e 4, constatou-se que aos 30 e 44 DAB a participação da biomassa de $B$. plantaginea foi proporcionalmente significativa $(80 \%$ e $56 \%$ do total, respectivamente), porém os valores absolutos foram baixos. Já a partir de 44 DAB a participação de $B$. plantaginea na biomassa foi nula.

Trabalhos conduzidos em casa de vegetação, ministrando-se solução nutritiva completa e sem a presença da cana-de-açúcar, estudaram o crescimento e a absorção de nutrientes por I. nil (Duarte, 2006), I. quamoclit

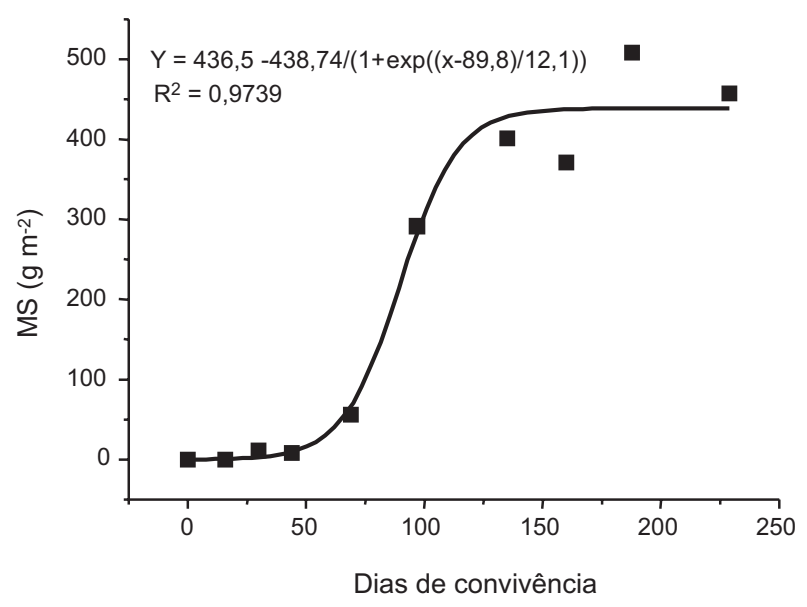

Figura 3 - Massa seca total da comunidade infestante acumulada após convivência por períodos crescentes com a cultura da cana-de-açúcar 
(Bianco et al., 2008a), I. grandifolia (Bianco et al., 2008b) e I. hederifolia (Guzzo, 2007). Todos observaram grande aumento da massa seca a partir do segundo terço do ciclo de desenvolvimento, principalmente dos caules. Nesses trabalhos, o acúmulo máximo de massa seca por planta ocorreu aos 146 dias após a emergência (DAE) para I. quamoclit $(6,46 \mathrm{~g}$ por planta), aos 119 DAE para I. nil (31,91 g por planta), aos 147 DAE para I. hederifolia (29,69 g por planta) e aos 192 DAE para I. grandifolia $(28,76 \mathrm{~g}$ por planta). No caso de I. hederifolia, uma planta, por ocasião do máximo acúmulo de massa seca, apresentou $726,82 \mathrm{mg}$ por planta de $\mathrm{N}$, $51,75 \mathrm{mg}$ por planta de $\mathrm{P}, 810,02 \mathrm{mg}$ por planta de $\mathrm{K}, 349,87 \mathrm{mg}$ por planta de $\mathrm{Ca}$, $148,03 \mathrm{mg}$ por planta de $\mathrm{Mg}$ e $64,43 \mathrm{mg}$ por planta de S (Guzzo, 2007).

Atentando-se à cultura da cana-de-açúcar e analisando os dados referentes à densidade de colmos por metro, observou-se que a manutenção do canavial livre da presença de plantas daninhas durante todo o ciclo resultou em 10,68 colmos $\mathrm{m}^{-2}$ por ocasião da estimativa da produtividade. Por outro lado, a convivência da comunidade infestante com a cultura até $229 \mathrm{DAB}$ resultou em 7,06 colmos $\mathrm{m}^{-2}$, o que corresponde a uma redução de $34 \%$ (Figura 5).

Em relação à produtividade da cana-deaçúcar, verificou-se que foi, em média, de 71,65 t ha $^{-1}$ na ausência total de competição

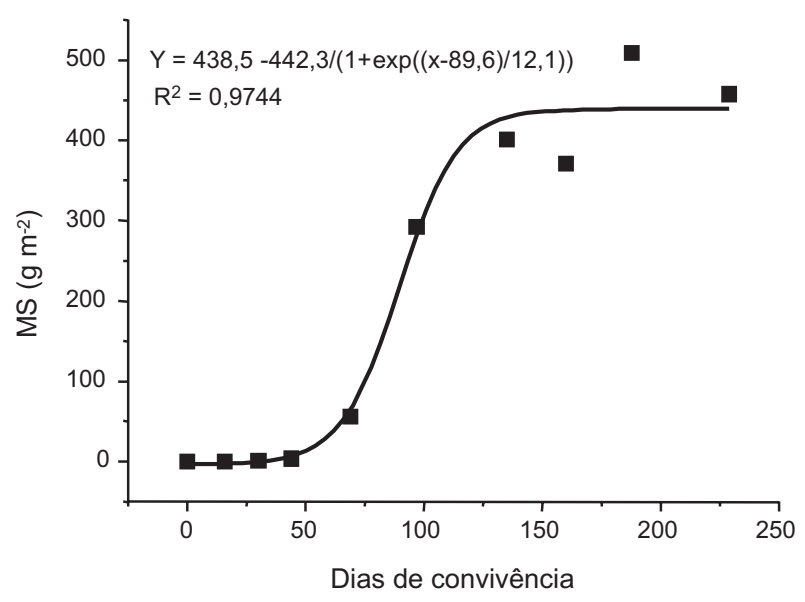

Figura 4 - Massa seca total de I. hederifolia acumulada após convivência por períodos crescentes com a cultura da canade-açúcar.

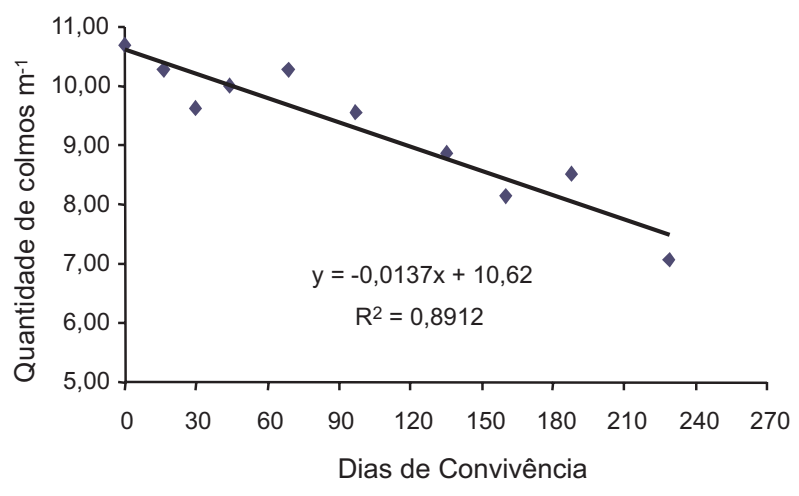

Figura 5 - Número de colmos de cana-de-açúcar após convivência por períodos crescentes com uma comunidade infestante com predomínio de I. hederifolia.

com a comunidade infestante. Contudo, quando a convivência entre comunidade infestante e cana-de-açúcar ocorreu até $229 \mathrm{DAB}$, a produtividade foi reduzida para $38,59 \mathrm{t} \mathrm{ha}^{-1}$, correspondendo a uma redução de $46 \%$ (Figura 6). Também para condições de canasoca colhida na época úmida, Meirelles et al. (2009) obtiveram redução de $42,4 \mathrm{t} \mathrm{ha}^{-1}$, o que correspondeu a $33,4 \%$. Para cana-planta de 18 meses o potencial máximo de redução foi de 47,5\% (Kuva et al., 2003) convivendo com infestação mista de capim-braquiária, capimcolonião e dicotiledôneas; de $82 \%$ convivendo com infestação predominantemente de capimbraquiária (Kuva et al., 2001); e de 20\% quando a infestação foi basicamente de tiririca (Kuva et al., 2000). A produtividade foi afetada de forma gradativa à medida que se aumentou o período de convivência entre comunidade infestante e cana-de-açúcar (Figura 6). Dessa forma, de uma produção máxima estimada em $66,7 \mathrm{t} \mathrm{ha}^{-1}$, cada dia de convivência da cultura da cana-de-açúcar com a comunidade infestante com predominância de $I$. hederifolia resultou em uma perda de $0,12 \mathrm{tha}^{-1}$.

Considerando arbitrariamente como tolerável uma perda de $5 \%$ na produção da cultura, estimou-se o período anterior à interferência (PAI) em 33 dias, ou seja, pode-se aguardar até $33 \mathrm{DAB}$ para que seja realizado o controle da comunidade de plantas daninhas, especialmente de I. hederifolia (Figura 6). Na prática, esse resultado indica que o controle pode ser realizado em pré-emergência das plântulas de I. hederifolia ou na pós-emergência inicial. 


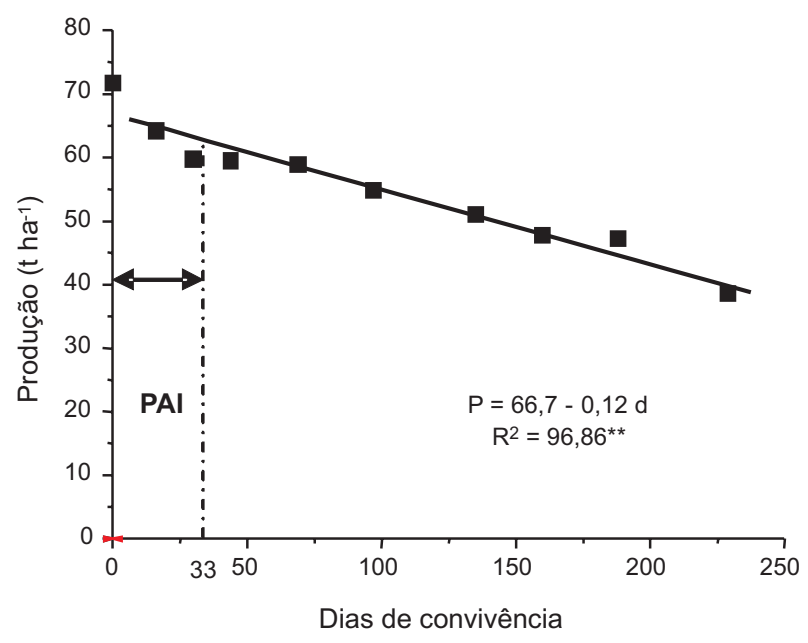

Figura 6 - Estimativa da produtividade da cultura de cana-deaçúcar após convivência por períodos crescentes com uma comunidade infestante com predomínio de I. hederifolia.

Para a modalidade de controle em pós-emergência, existem herbicidas que apresentam eficácia mesmo com as cordas-de-viola em estádio avançado de desenvolvimento. Alguns desses produtos estão sendo utilizados pelas usinas em caráter emergencial, para viabilizar a colheita. No entanto, pelo resultado obtido neste experimento, é provável que estejam, ocorrendo perdas significativas de produtividade pela interferência. Em relação à extensão do período de controle, ou seja, do período residual de controle requerido, é necessária a determinação do periodo total de prevenção à interferência (PTPI) descrito por Pitelli (1985). Segundo esse mesmo autor, quanto maior for o período de convivência mútua entre a cultura e a comunidade infestante, maior será a interferência, mas esta dependerá também da época em que esse período for concedido.

Analisando o resultado obtido no presente estudo e os resultados encontrados na literatura, no caso de cana-soca para distintos padrões de composição da comunidade de plantas daninhas, constatou-se que o período anterior à interferência foi mais curto do que o obtido por Resende Sobrinho (1983), que foi de 56 DAB, e mais longo que aqueles obtidos por Gravena et al. (2001) e Meirelles et al. (2009), que foram de 18 e 28 DAB, respectivamente.

Para as condições de cana-planta de 18 meses, cujo plantio é realizado no primeiro semestre de cada ano, vários trabalhos foram realizados. Quando o predomínio foi de Cyperus rotundus, obteve-se como limite 41 dias de convivência (Kuva et al., 2000). Para uma comunidade com predomínio de Brachiaria decumbens, obteve-se o período anterior à interferência (PAI) de 89 dias após o plantio (Kuva et al., 2001). Finalmente, para uma comunidade predominantemente de Brachiaria decumbens e Panicum maximum, esse período foi de 74 dias (Kuva et al., 2003).

Em relação às características qualitativas do caldo, não foi observada grande variação para porcentagem de fibra, brix, pol e pureza do caldo (Tabela 1). Por outro lado, verificou-se que o valor do açúcar total recuperável (ATR) por unidade de massa $\left(\mathrm{kg} \mathrm{t}^{-1}\right)$ tendeu a crescer com o aumento do período de convivência.

Tabela 1 - Resultados da análise qualitativa das amostras compostas de cada tratamento

\begin{tabular}{|c|c|c|c|c|c|c|}
\hline $\begin{array}{c}\text { Período de } \\
\text { convivência }\end{array}$ & Fibra (\%) & Brix (\%) & Pol (\%) & Pureza (\%) & ATR $\left(\mathrm{kg} \mathrm{t}^{-1}\right)$ & ${\text { ATR }\left(\mathrm{kg} \mathrm{ha}^{-1}\right)}$ \\
\hline 0 & 10,86 & 18,87 & 14,27 & 75,71 & 125,64 & 9002,23 \\
\hline $0-16 \mathrm{DAB}$ & 10,58 & 18,73 & 14,33 & 76,52 & 126,48 & 8116,03 \\
\hline $0-30 \mathrm{DAB}$ & 10,84 & 19,23 & 15,37 & 79,82 & 133,55 & 7973,13 \\
\hline $0-44 \mathrm{DAB}$ & 11,37 & 18,57 & 14,28 & 76,81 & 124,67 & 7406,01 \\
\hline $0-69 \mathrm{DAB}$ & 11,14 & 18,80 & 14,64 & 77,83 & 127,45 & 7502,71 \\
\hline $0-97 \mathrm{DAB}$ & 11,66 & 18,97 & 14,72 & 77,54 & 126,91 & 6951,43 \\
\hline $0-135 \mathrm{DAB}$ & 11,84 & 19,10 & 15,20 & 79,65 & 129,96 & 6632,58 \\
\hline $0-160 \mathrm{DAB}$ & 11,87 & 19,57 & 15,83 & 80,93 & 134,66 & 6431,98 \\
\hline $0-188 \mathrm{DAB}$ & 10,97 & 19,60 & 15,51 & 79,11 & 134,55 & 6359,26 \\
\hline $0-229 \mathrm{DAB}$ & 11,37 & 19,63 & 15,86 & 80,75 & 136,08 & 5251,05 \\
\hline
\end{tabular}

DAB - dias após o cultivo e adubação e início da brotação da cana. 
Nos diversos trabalhos de matocompetição na cultura da cana, outros autores avaliaram características tecnológicas, porém em nenhum deles houve qualquer indício de alteração significativa no valor de ATR. Esse fato pode ter ocorrido devido ao estresse imposto pela presença de I. hederifolia sobre a cana, induzindo a antecipação no processo de maturação desta. A confirmação desse fato precisa ser investigada com outros estudos que envolvem comunidades de plantas daninhas com predomínio de espécies trepadeiras ou prostradas. Contudo, quando se considera conjuntamente o valor do ATR do caldo e a produtividade de cada tratamento, ou seja, o valor em $\mathrm{kg}$ de ATR ha ${ }^{-1}$, observa-se tendência de superioridade nos tratamentos com menor convivência (Figura 7). Esse resultado significa que para cada dia de convivência com a comunidade infestante há redução de 13,12 kg de ATR ha-1, considerando produtividade estimada em $8.433 \mathrm{~kg}$ de ATR ha ${ }^{-1}$.

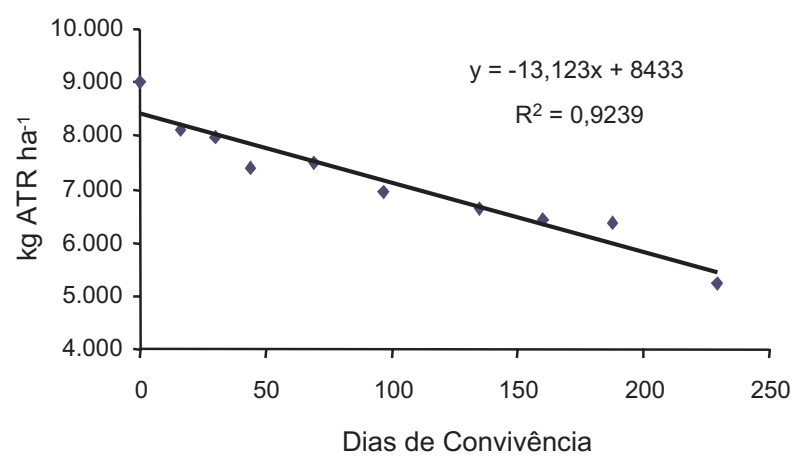

Figura 7 - Quantidade de açúcar total recuperável presente no caldo da cana-de-açúcar após períodos crescentes de convivência com a comunidade infestante com predomínio de I. hederifolia .

Os resultados obtidos neste experimento demonstraram que a cultura da cana-deaçúcar (cana-soca), variedade RB855536, com última colheita na época úmida pode conviver com uma comunidade infestante predominantemente de Ipomoea hederifolia até 33 DAB sem que ocorram prejuízos qualitativos e quantitativos à cultura. Concluiu-se, ainda, que o potencial de redução do número de final de colmos e da produtividade foi de $34 \%$ e $46 \%$, respectivamente.

\section{AGRADECIMENTOS}

Ao Departamento Agrícola da Usina Andrade, pela cessão da área para instalação do experimento e pelo apoio na execução dos trabalhos de campo.

\section{LITERATURA CITADA}

AZANIA, A. A. P. M. et al. Interferência da palha de cana-deaçúcar (Saccharum spp.) na emergência de espécies de plantas daninhas da família Convolvulaceae. Planta Daninha, v. 20, n. 2, p. 207-212, 2002.

BIANCO, S. et al. Acúmulo de massa seca e macronutrientes por plantas de Ipomoea quamoclit L. In: CONGRESSO BRASILEIRO DA CIENCIA DAS PLANTAS DANINHAS, 26., 2008, Ouro Preto. Resumos... Ouro Preto: Sociedade da Ciência das Plantas Daninhas, 2008a. CD ROM.

BIANCO, S. et al. Acúmulo de massa seca e macronutrientes por plantas de Ipomoea grandifolia (Dammer.) O'don. In: CONGRESSO BRASILEIRO DA CIÊNCIA DAS

PLANTAS DANINHAS, 26., 2008, Ouro Preto. Resumos... Ouro Preto: Sociedade da Ciência das Plantas Daninhas, 2008b. CD-ROM

DUARTE, D. J. Crescimento e nutrição mineral de plantas de Ipomoea nilederifolia (L.) 2006. $75 \mathrm{f}$. Monografia (Trabalho de Graduação em Agronomia) Universidade Estadual Paulista, Jaboticabal, 2006

GRAVENA, R.; KUVA, M. A.; PITELLI, R. A. Períodos de Interferência de plantas daninhas em soqueira de cana-deaçúcar (Saccharum spp.). In: CONGRESSO DELA ASSOCIACIÓN LATINO AMERICANA DE MALEZAS, 15., 2001, Maracaibo. Resumos... Maracaibo: SOVECOM, 2001. p. 102

GRAVENA, R. et al. Controle de plantas daninhas através da palha de cana-de-açúcar associada à mistura dos herbicidas trifloxysulfuron sodium + ametrina. Planta Daninha, v. 22, n. 2, p. 419-427, 2004.

GUZZO, C. D. Crescimento e nutrição mineral de Ipomoea hederifolia L. 2007. 60 f. Monografia (Trabalho de Graduação em Agronomia) - Universidade Estadual Paulista, Jaboticabal, 2007.

KUVA, M. A. et al. Períodos de interferência das plantas daninhas na cultura da cana-de-açúcar. I- Tiririca. Planta Daninha, v. 18, n. 2, p. 241-251, 2000.

KUVA, M. A. et al. Períodos de interferência das plantas daninhas na cultura da cana-de-açúcar. II - Capim-braquiária (Brachiaria decumbens). Planta Daninha, v. 19, n. 3, p. 323-330, 2001.

Planta Daninha, Viçosa-MG, v. 27, n. 2, p. 265-272, 2009 
KUVA, M. A. et al. Períodos de interferência das plantas daninhas na cultura da cana-de-açúcar. III - Capimbraquiária (Brachiaria decumbens) e Capim-colonião (Panicum maximum). Planta Daninha, v. 21, n. 1, p. 37-44, 2003.

KUVA, M. A. Banco de sementes, fluxo de emergência e fitossociologia de comunidade de plantas daninhas em agroecossistema de cana crua. 2006. 105 f. Tese

(Doutorado em Produção Vegetal) - Universidade Estadual Paulista, Jaboticabal, 2006

KUVA, M.; PITELLI, R. A.; SALGADO, T. P.

Fitossociologia de comunidades de plantas daninhas em agroecossistema cana-crua. Planta Daninha, v. 25, n. 3, p. 501-511, 2007.
MARTINS, D. et al. Emergência em campo de dicotiledôneas infestantes em solo coberto com palha de cana-de-açúcar. Planta Daninha, v. 17, n. 1, p. 151-161, 1999.

MEIRELLES, G;; ALVES, P. L. C. A.; NEPOMUCENO, M. P. Determinação dos períodos de convivência da cana-soca com plantas daninhas. Planta Daninha, v. 27, n. 1, p. 67-73, 2009.

PITELLI, R. A. Interferência de plantas daninhas em culturas agrícolas. Inf. Agropec., v. 11, n. 129, p. 16-27, 1985.

REZENDE SOBRINHO, E. A. Efeitos de períodos de matocompetição sobre a produtividade e características tecnológicas da cana-de-açúcar, em soca de 1o corte. 1983. 43 f. Monografia (Trabalho de Graduação em Agronomia) Universidade Estadual Paulista, Jaboticabal, 1983 